\title{
Detection of leakage current in Formula Electric by Voltage Measurement Method
}

\author{
Thanabodi Yatbamrung ${ }^{1}$, Tawat Chuchit $^{1}$ and Thanatchai Kulworawanichpong ${ }^{1}$ \\ ${ }^{1}$ School of Electrical Engineering, Institute of Engineering, Suranaree University of Technology, Nakhon \\ Ratchasima 30000 Thailand
}

\begin{abstract}
This paper presents leakage current detection in Formula Electric by a voltage measurement method. The voltages across metal bars in a vehicle structure are measured and compared with the 2016 FASE electrical inspection requirement and IEC 62305-3 standard. The leakage current can also be determined by Ohm's law. The results show that the maximum measured voltage is $0.047 \mathrm{~V}$. It is obvious that the maximum voltage does not exceed the acceptable value imposed by the requirement and standard. Therefore, this Formula Electric is safe to run in terms of leakage current.
\end{abstract}

Keywords: Formula Electric, leakage current, voltage measurement method

\section{Introduction}

A fossil fuel has dominated the use of energy in transportation and industries for several decades. The process of obtaining this energy is not environmentally friendly and the supply of resources is not sustainable. As a result, renewable energy is currently more feasible and wildly used in many applications. Several forms of energy are simply transformed into electrical energy which is easy to use for energy users. Nowadays, various modes of transport are increasingly electrified for the sake of economy and environment. To encourage the use of clean energy, a Formula Electric competition is put forward and currently held both domestically and internationally. For student Formula Electric, the prototype and the first SUT Formula Electric was created by a group of researchers at Suranaree University of Technology (SUT) and took part in the first Formula Electric competition in Thailand. The instantaneous traction power must not exceed $80 \mathrm{~kW}$ and every mechanic and electrical designs must comply with FSAE inspection requirements. The Formula Electric is required to be thoroughly inspected following the mentioned requirements before competition. The electrical requirements include traction systems, low voltage grounding systems, charging circuits, and electrical protection systems. This study pays attention to electrical protection systems which have several aspects such as resistance measurement between positive and negative electrodes of a battery, tractive voltage measurement, voltage measurement between low voltage conductive parts and a metal structure, and voltage and resistance measurement at a metal bar of the structure etc. Then, this paper focuses on the voltage measurement of the metal structure in order to indirectly determine the leakage current in the structure.

Many aspects of leakage current detection have been researched in the past, for example, leakage current detection by resistance measurement [1-3], voltage measurement without vehicle movement [1-4], leakage current warning if an amount of leakage current is not safe for humans [5, 6]. In addition, leakage current detection by voltage measurement during driving is also studied [7].

This study presents leakage current detection in the SUT Formula Electric by voltage measurement at the metal structure when the vehicle is driven. The measured voltages are compared with those specified by the 
FASAE inspection requirements and IEC 62305-3 standard. Fig. 1 illustrates the voltage measurement across one of the metal bars of the vehicle structure, i.e. the length across which the voltage is measured is $10 \mathrm{~cm}$. The SUT Formula Electric is hereafter referred to as only Formula Electric.

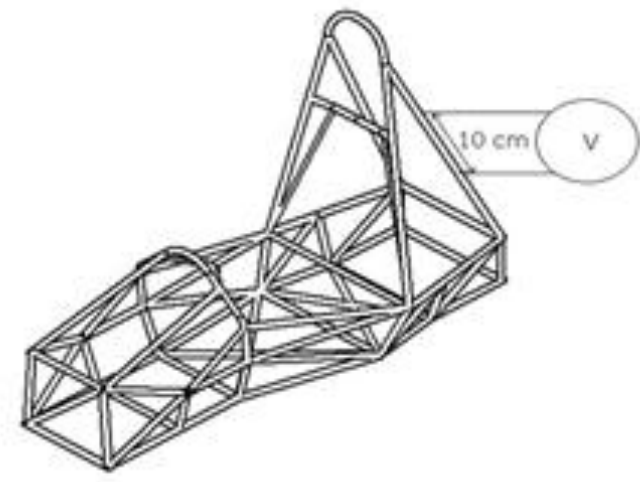

Fig. 1 voltage measurement at the metal structure

\section{Formula Electric Components}

Given the limited space in the Formula Electric, only important and necessary accessories and/or equipment have to be fitted and arranged for optimal and safe use of space according to FSAE inspection requirements. The components in the Formula Electric consist of a 96 V 50 Ah battery for traction supply, a 12 V 7.5 Ah auxiliary battery, a traction inverter and controller, a gearbox, a DC-DC converter, and traction switch box etc. as shown in Fig. 2.

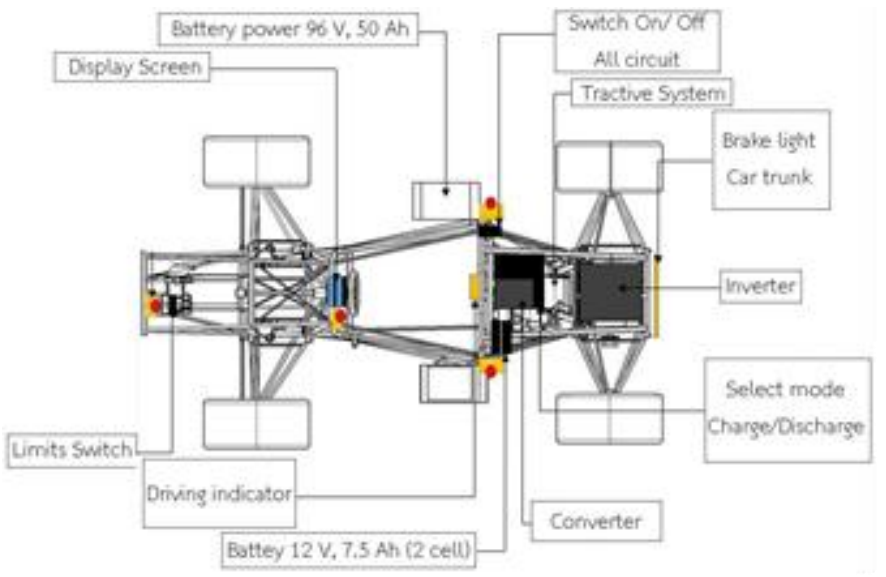

Fig. 2 Formula Electric components

\section{Leakage current in electric vehicles}

There are two methods to detect leakage current in electric vehicles: resistance measurement and voltage measurement method. According to the FSAE electric inspection requirements, the resistance must not exceed $0.3 \Omega$ and the voltage must not exceed $0.1 \mathrm{~V}$ [1]. For IEC 62305-3 standard, the acceptable resistance and voltage are specified at less than $0.3 \Omega$ and $1 \mathrm{~V}$, respectively [2]. 


\section{Voltage measurement}

The resistance and voltage measurement have to be taken at the given points where it is likely to have leakage currents in the vehicle metal structure shown in Fig. 3. This section explains the collection of the measured voltage. The data measurement and collection kit is composed of a voltage sensing circuit and a data logger.

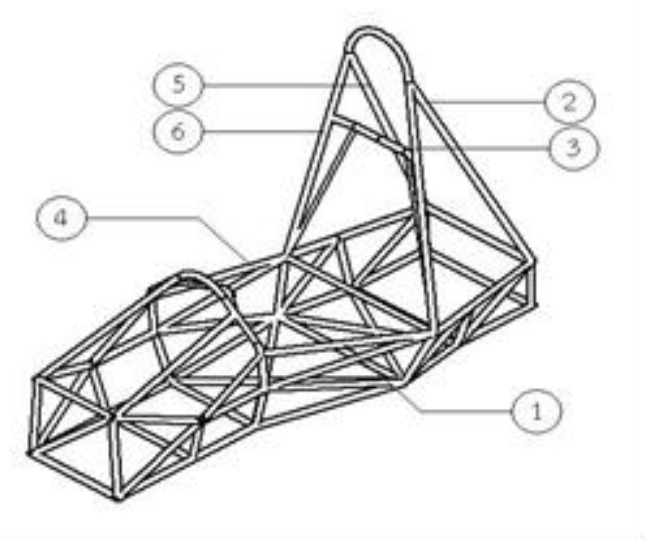

Fig. 3 Voltage measurement locations

\subsection{Voltage measurement circuit}

The voltage measurement circuit amplifies the measured voltage which has a range of $0.1-1 \mathrm{~V}$ as shown in Fig. 4. The first part of the circuit is a voltage sensing circuit using a differential amplifier. Part 2 and part 3 are an inverting op-amp circuit and signal conditioner circuit, respectively, to amplify and adjust the voltage signal to be compatible with the microcontroller. This circuit is part of the data measurement and collection module as in Fig. 5.

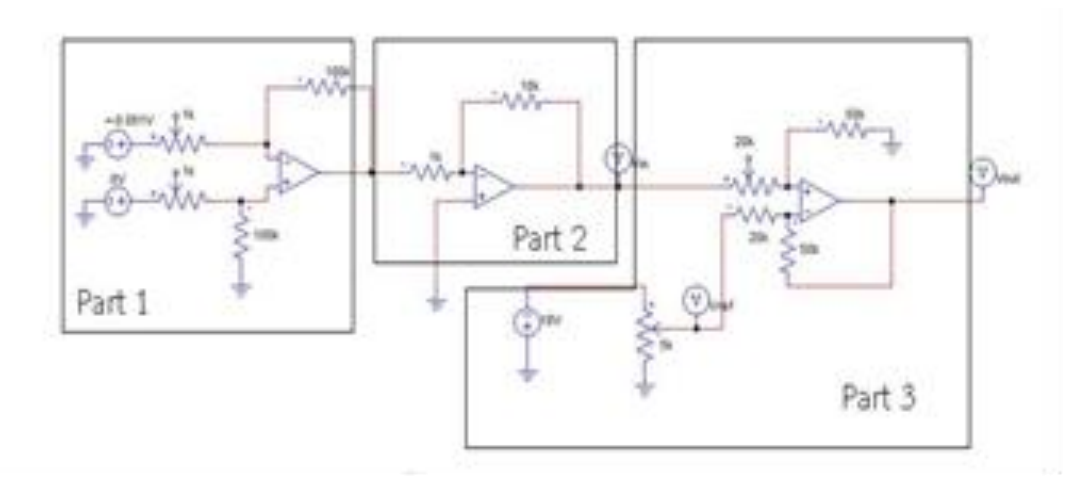

Fig. 4 Voltage measurement circuit

\subsection{Data measurement and collection kit}

In order to collect, process, and display the measured data, an Arduino Nano as a microcontroller; DC-DC converter; real time clock (RTC) for date and time stamp; SD card module as a data logger; LCD screen; potentiometer; and op-amp UA741 are used to create the data measurement and collection system. Fig. 5 shows all components in the data measurement and collection kit. 


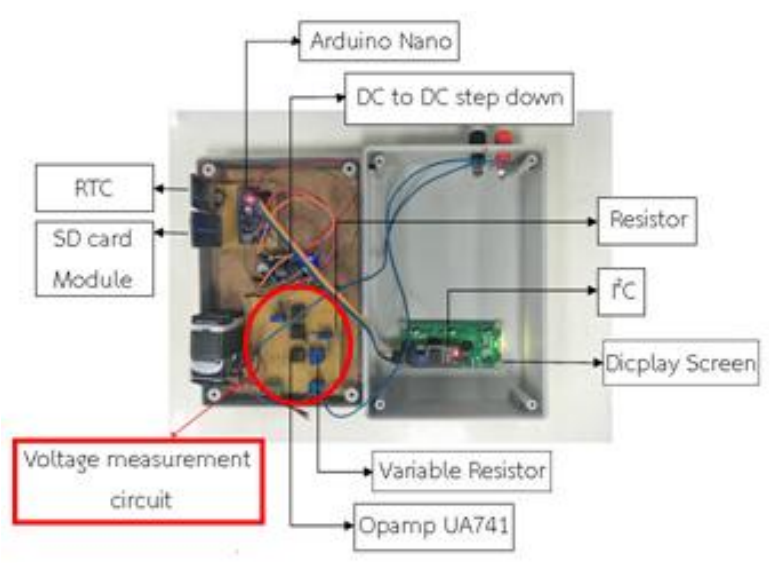

Fig. 5 Data measurement and collection kit

\section{Results}

The Formula Electric has been driven for six rounds, i.e. it took one minute in each round, during the drive, the voltage measurement has been taken for one measurement point at a time. The details of the measurement points and locations are described earlier in section 1 and 4. Eventually, six sets of the measured data have been collected and plotted as in Fig. 6-11. Also, the traction voltages and currents were plotted in Fig. 6-11 to enhance the comparison with the values from the voltage measurement circuit.

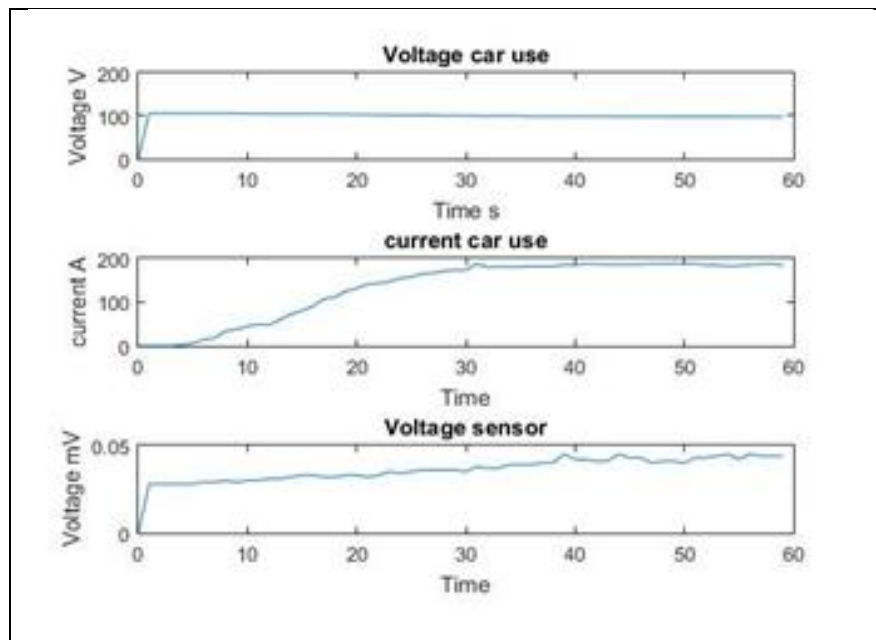

Fig. 6 Traction voltage, traction current, and the measured voltage from the kit at measurement point no. 1
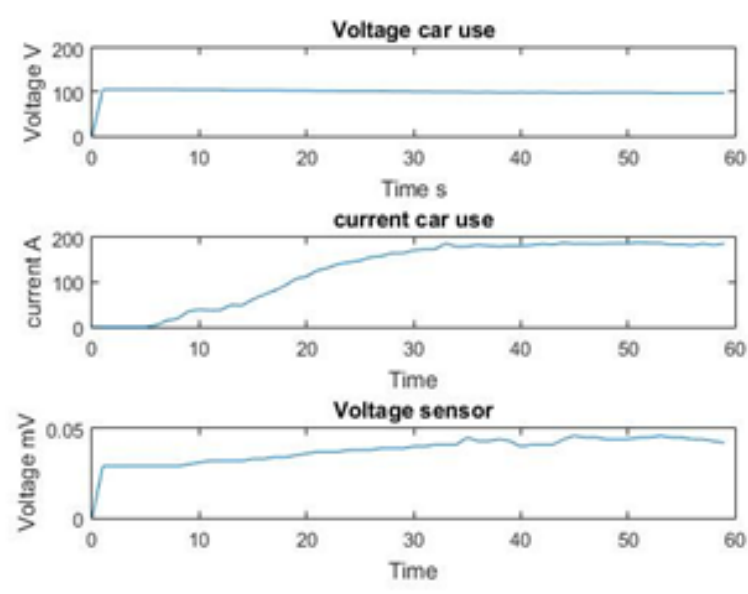

Fig. 8 Traction voltage, traction current, and the measured voltage from the kit at measurement point no. 3
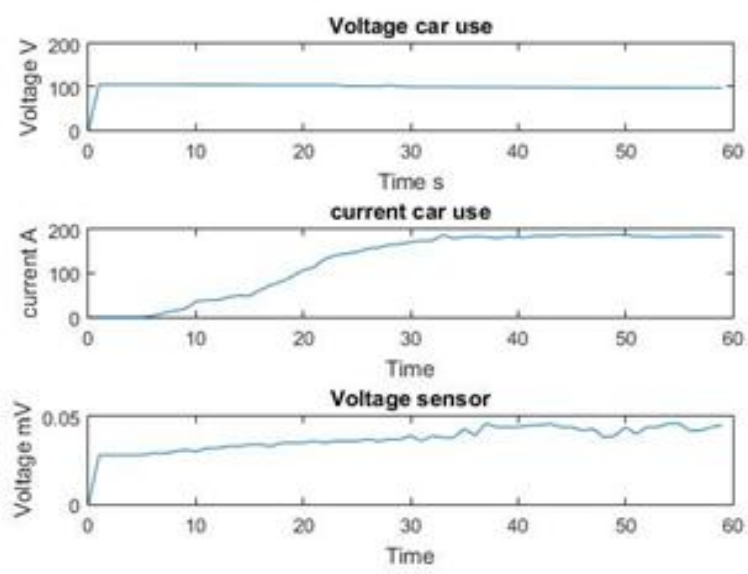

Fig. 7 Traction voltage, traction current, and the measured voltage from the kit at measurement point no. 2
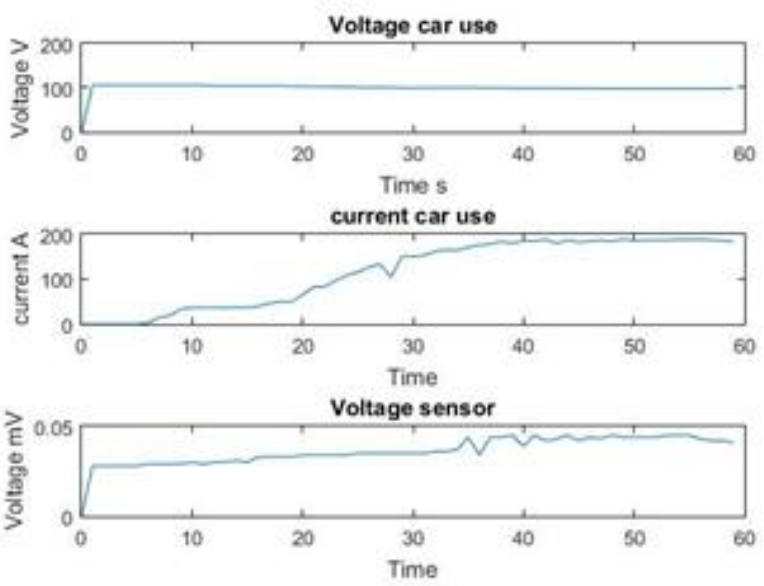

Fig. 9 Traction voltage, traction current, and the measured voltage from the kit at measurement point no. 4 


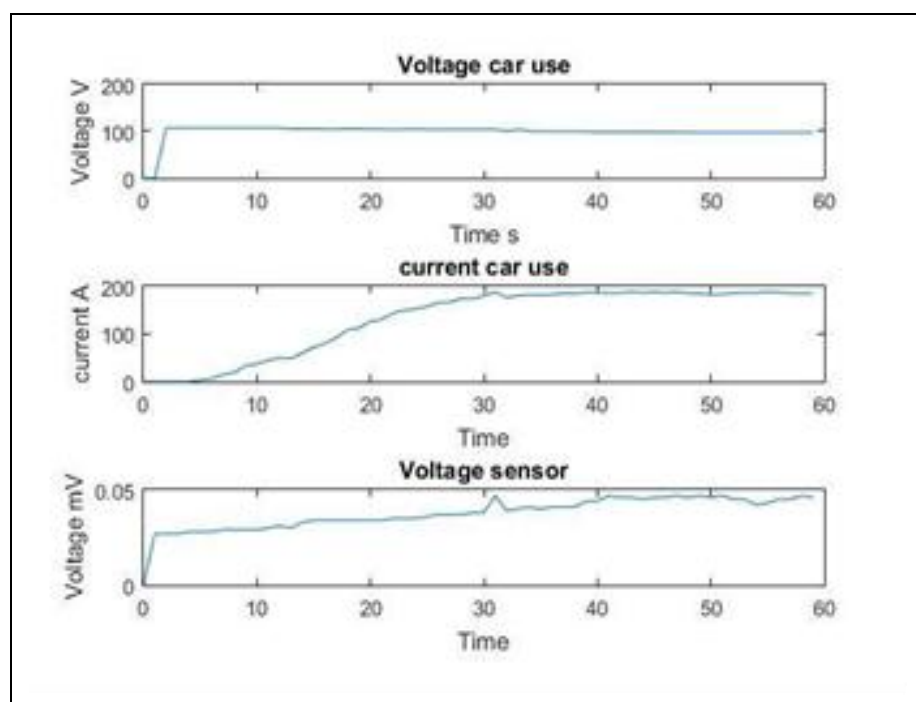

Fig. 10 Traction voltage, traction current, and the measured voltage from the kit at measurement point no. 5
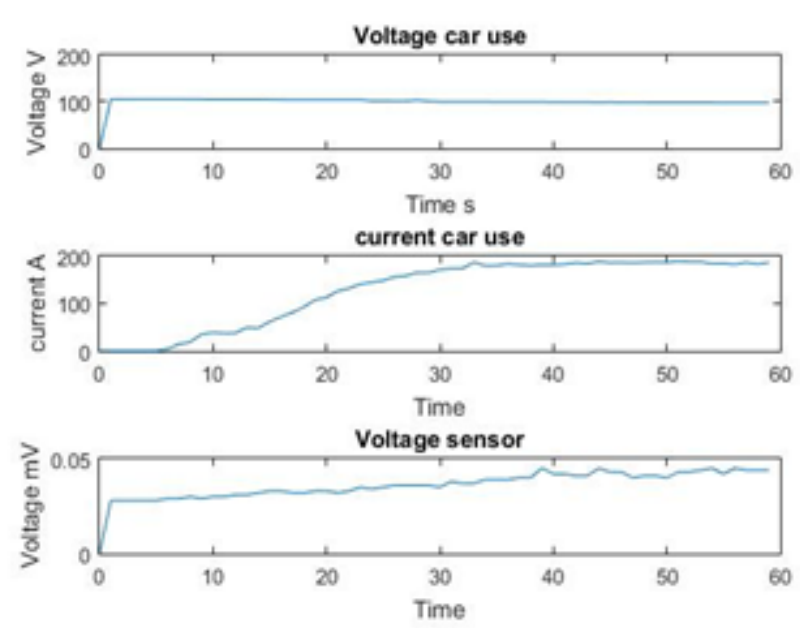

Fig. 11 Traction voltage, traction current, and the measured voltage from the kit at measurement point no. 6

From Fig. 6-11, the traction voltage during the drive was almost constant at approximately $100 \mathrm{~V}$. The traction current started from zero, continuously increased, and levelled out after 30 seconds. The measured voltage from the kit slightly increased with the traction current and seemed to be constant after 30 seconds as well. The maximum measured voltages were summarized in Table 1.

Table I. Average voltage measurement while moving cars.

\begin{tabular}{|c|c|c|c|}
\hline $\begin{array}{c}\text { Measurement } \\
\text { point No. }\end{array}$ & $\begin{array}{c}\text { Traction } \\
\text { Voltage (V) }\end{array}$ & $\begin{array}{c}\text { Traction } \\
\text { Current (A) }\end{array}$ & $\begin{array}{c}\text { Measured } \\
\text { voltage }(\mathrm{mV})\end{array}$ \\
\hline 1 & 98.6 & 189.1 & 0.047 \\
\hline 2 & 98.2 & 185.8 & 0.046 \\
\hline 3 & 99.1 & 188.7 & 0.046 \\
\hline 4 & 98.2 & 188 & 0.046 \\
\hline 5 & 97.6 & 188.6 & 0.047 \\
\hline 6 & 98.2 & 188.7 & 0.047 \\
\hline \multicolumn{3}{|c|}{ Maximum } & 0.047 \\
\hline
\end{tabular}

Table 1 showed that the mean value of the measured voltage from the kit was less than $0.05 \mathrm{mV}$, which complied with both the FSAE electric inspection requirements and IEC 62305-3 standard.

The leakage current in the vehicle structure can be determined by Ohm's law as in (1) and using the measured voltage and resistance from the kit. The leakage current occurred in the test was 0.2-0.3 mA shown in Table 2, which was less than $5 \mathrm{~mA}$. It is proved that the Formula Electric is safe in terms of leakage currents according to the FSAE electric inspection requirements and IEC 62305-3 standard.

$$
V=I R
$$

Table II. Leakage current at each measurement point.

\begin{tabular}{|c|c|c|c|}
\hline Measurement point No. & Resistance $(\mathrm{m} \Omega)$ & Measured voltage $(\mathrm{mV})$ & Leakage current (mA) \\
\hline 1 & 150.33 & 0.047 & 0.313 \\
\hline 2 & 167 & 0.046 & 0.275 \\
\hline 3 & 126 & 0.046 & 0.365 \\
\hline 4 & 119.33 & 0.046 & 0.385 \\
\hline 5 & 149 & 0.047 & 0.315 \\
\hline \multicolumn{2}{|c|}{138.67} & 0.047 & 0.339 \\
\hline \multicolumn{2}{|c|}{ Maximum } & 0.047 & 0.313 \\
\hline
\end{tabular}




\section{Conclusion}

This paper presented leakage current detection in Formula Electric by a voltage measurement method. The voltages across six metal bars or six locations in the vehicle structure were measured during the drive test using the data measurement and collection kit created by the researcher and compared with the 2016 FASE electrical inspection requirement and IEC 62305-3 standard. The results showed that the maximum measured voltage was $0.047 \mathrm{~V}$, which did not exceed 0.1 according to the FSAE electric inspection requirements and did not exceed 1 $\mathrm{V}$ according to IEC 62305-3 standard. The leakage current was less than 0.4 mA. Therefore, this Formula Electric was safe to drive in terms of leakage currents.

\section{References}

[1] “2016 FSAE Electric Inspection Sheet.” (2016) online, : www.fsaeonline.com, [25 December 2017]

[2] IEC 62305 Part 3, Protection against lightning - Part 3: Physical damage to structures and life hazard, Earthtermination system: Earthing arrangement in general conditions, 2010, pp. 24-27

[3] Fernando Augusto, Herrera León, Mauricio Andrés, Páez Prieto, José Manuel, Páez Quevedo,, "Design and Construction of a Dynamic System for Step and Touch Voltage Measurements for Grounding Systems," 2011 International Symposium on Lightning Protection (XI SIPDA), Fortaleza, Brazil, October 3-7, 2011, pp. 278 - 283

[4] Guo Yan, Zhou Rong, Liu Guibin and Naoki Kinoshita, "Research of Measurement Method about Electric Vehicle High Voltage System Isolation Resistance," ITEC Asis-Pacific 31 Aug.-3 Sept. 2014, pp. 1 - 5

[5] Padung Kitsawang, "Real-time Alarming System of Dangerous Leakage Current at Distribution Transformer via Digital Signal Processing,” The Journal of Industrial Technology, Vol. 12, No. 3 , September - December 2016, pp. $1-13$

[6] Srivichai and W. Plueksawan, "DangerousLeakage Current Alarming Device A Case Study of Dangerous Leakage Current in Public Area", Proceedings of the 7th KU-KPS Conference, Bangkok, Thailand, 2010, pp. 1758-1766

[7] Zhao chunming, Li qing, "Research on On-line Monitoring Methods of High Voltage Parameter in Electric Vehicles," World Electric Vehicle Journal Vol. 4 - ISSN 2032-6653 - (c) 2010 WEV, Shenzhen, China, Nov 5-9, 2010, pp. 1 - 6 